\title{
Energy demand of occupant's spatial modification in residential buildings. Case study of Médéa, Algeria
}

\author{
Boukarta Soufiane ${ }^{1,2 *}$, Berezowska - Azzag Ewa ${ }^{2}$ \\ ${ }^{1}$ Institut d'Architecture et d'Urbanisme (IAU), university of Blida 1. Algeria \\ ${ }^{2}$ Ecole polytechnique d'Architecture et d'Urbanisme (EPAU), Laboratoire Ville, Urbanisme et Développement \\ Durable (VUDD). Algiers, Algeria. \\ *e-mail: boukarta.soufiane@univ-blida.dz
}

\begin{abstract}
Housing is rated as one of the most commonly consuming energy field in terms of energy end-use with $41 \%$. Regarding the transformations dealt by dwellers for functional and social uses. The aim of this paper is: Firstly, to highlight the non-controlled transformation process made by the occupant in Algeria; Secondly, to explore the impact of the energy load of such spatial transformations. The question is approached in two tracks, (i) Through Ecotect software's simulations (ii) and measurements through a collection of energy end-use data. Basically, the energy demand is bound to dwelling's spatial and socioeconomic criteria. Three cases studied showed consequently 2 positive and 1 negative energy load, in which two explanations may be given: Insulation quality that occupant is lacking facilities to improve may be stated as a physical explanation, as well as for the socio economic one, the density per dwelling plays a major role, but it is the income which explains within the two approaches more than $87 \%$ of the energy end use.
\end{abstract}

Key words: Energy load; occupant; dwelling modifications; simulations, Greenhouse Gas Emission.

\section{Nomenclature}

\begin{tabular}{ll}
\hline $\mathrm{Kwh} / \mathrm{m}^{2} / \mathrm{y}$ & Kilowatt hour $/ \mathrm{m}^{2} /$ year \\
EPI & Energy Performance Index. \\
ROH & Rate Occupancy per Housing \\
GHG & Greenhouse gas emission \\
G & Gram \\
DA & Algerian Dinar \\
\hline
\end{tabular}

\section{Introduction}

Controlling the climate changes is one of the main challenges of the 21th century. It's very important that all the countries across the world has to be committed in this way. It seems that a raise of $0.1^{\circ}$ every decade until 2100 [4] is already inevitable because of the life cycle of the greenhouse gases which are already emitted. In order to reduce an estimated level of $2{ }^{\circ} \mathrm{C}$, a 
gathering conference for all participant countries took place recently in Paris COP21 and in Marrakech COP22. As a member, Algeria submitted its commitment through a set of guides and financial support $[10,17]$ for the industrial, residential and transport sectors. For the residential one, a goal of $37 \%$ of renewable energy is considered for 2030's horizon.

Housing in Algeria is the most important sector in terms of energy consumption with a ratio of $41 \%$ of the total energy end-use. Due to housing crisis in Algeria, an erecting program of three million housing in 15 years was launched as a presidential commitment. The Algerian housing stock is characterized by a high occupancy rate per housing with more than 5 persons and the housing's size is often composed of two bedrooms and one living room. In order to improve the dwelling's use, dwellers adapt their apartment with their own knowledge and without consulting an architect or an engineer.

In Algeria, to face the housing crisis, the Algerian president lunched a program of one million of housing every five years. In most cases, the dwellings have a similar floor plan which pushes dwellers to change their housings without expert (architect or engineer) consultations. In this paper, we aim to identify, by studying three cases, the energy load of the occupant adjustments. The following assets illustrate the elaborated method.

The occupant behavior constitutes the most important part of uncertainty using the simulation software to predict the energy demand. A set of studies has been carried out to identify the impact of this field. Mainly, we can already distinguish two approaches:

(a) Calibrating a presence profile of the user according to their space occupancy. To innumerate, Hassanabadi et al [6] has tested the importance of this field of researches by comparing two energy improvement scenarios. The first one adopts a structural approach which has been interpreted by the reduction of the cooling/heating volume and an increasing of the glazed area. The second scenario was just interpreted by implementing the software with the real flat occupancy. The occupants used the living room more than their bedrooms which are only used for resting. The situation is reversed during weekends where bedrooms are more occupied which means that the operating hours are longer compared to the working days. Based on a given timetable, the results demonstrate that the structural scenario improves the energy potential by 33\%, while the occupant's adjusted profile developed more energy saving up to $71 \%$ in cooling load. On the same track, Emery and Kippenhan [5] reported based on a survey of four nearly and identical houses. Two scenarios have been distinguished, firstly, by dividing the four houses in two pairs. Secondly, the insulation level was improved on one pair and the other pair was kept without insulation improvement. Only one house of each pair was occupied by the student's families. The results showed that the energy consumption increased in both occupied houses, and the house with the improved building envelope had a smaller increase.

(b)The second category of studies focuses on the occupant behavior. Ouyangand Hokao [11] has investigated 124 houses categorized in two clusters. Where the first cluster has been trained regarding the best practice which can improve the energy-saving while the second one was kept as a standard cluster without training. The results based on July 2008 measurements showed a difference of $10 \%$ between the two listed clusters. This percentage has to be the effective energy load of occupant behavior, but if we take this difference, we will find that there is an influence of the other three factors which are, the building design, urban context 
and the performance of the operating system, even if the sample of 124 households has been selected to reduce the effect of the other factors.

$\mathrm{Yu}$ et al [16] has proposed an approach to identify with more accuracy the energy load of occupant behavior. This approach consists on clusters. The purpose is to fix houses in a set of groups (clusters). Yu et al [16] results attest that identifying accurately the load energy of occupant is mainly done to imitate the occupant behavior in a rigid way because of the complexity of the occupant behavior. In order to restrain such complexity a set of studies focused on a single energy load activity regarding shading and lightning effects [7].

Hong and Lin [7] have proposed an approach based on energy simulation analysis of the occupant in offices. The research focused on offices occupied only by one person to reduce the complexity. The research purpose was to identify, understand and categorize occupant behavior that can have significant impact on energy use of offices. Through this study, three workstyles are set to recognize occupant behavior: (a) austerity workstyle which is interpreted by a proactive occupant profile aiming to save energy; (b) A referenced workstyle established as standard for all average energy users. (c) Wasteful workstyle representing all will energy users. The results based on simulation performed in Energy plus software show that an austerity work style lead to reduction of energy consumption by up to $50 \%$, whereas the wasteful one consumes up to $90 \%$ more energy.

\section{Research method}

Our paper focuses on the second category of the occupant behaviour, where we give interest to occupant actions in their own dwellings. Remarkably in Algeria, dwellings are spatially adapted after bought process. Adjustments are made by occupants without any experts' consultations for main reasons: (i) Changes are made in the indoor space of dwellings; (ii) Legislative deficiency permitting such widespread habits.

In our paper, three cases of dwellings are treated to evaluate the load energy of occupant spatial adjustments where it is adopted in three steps. (i) Quantifying the energy budget of dwellings before and after modifications. The energy load considers only the heating and cooling charges. To estimate the energy demand for cooling and heating simulations in Ecotect software were performed. The dwellings before modifications are considered as the reference case. This step aims to explain the energy load of the adjustments in a physical way. (ii) By introducing the real energy end-use for the three apartments and then we explain the energy use based on occupant profiles considering the socio-economic criteria. A comparative analysis was adopted based on simulation approach between dwellings before and after modifications. Whereas, for the measurement approach based on energy end-use acquired from bills' dwellings, it was impossible to compare dwellings' before and after modifications because modifications were made before the effective use of dwellings for both cases one and two, as well as for the third one. (iii) Analysing the energy load obtained from simulation and from end-use energy within a physical and socio-economical way. 


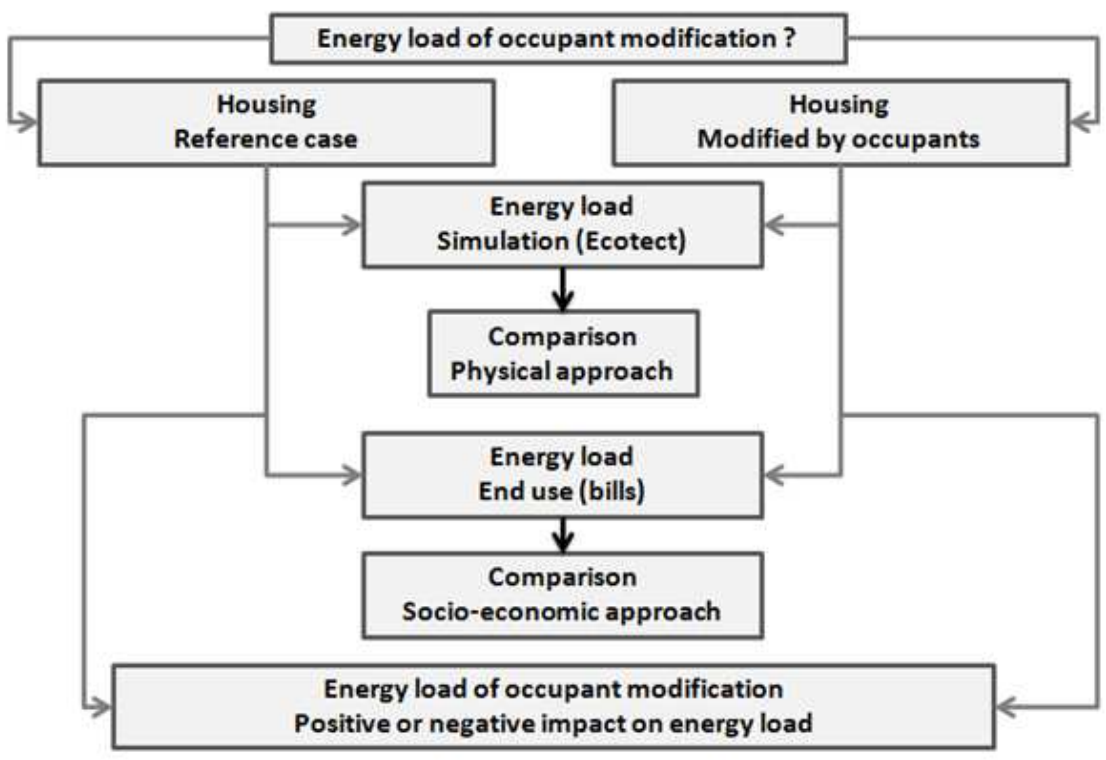

Figure 1 : Method framework.

\subsection{Climate zone}

The studied apartments are located in the city of Medea $\left(36.3^{\circ}\right.$ latitude and $2.8^{\circ}$ longitude). The climate is sub-humid characterized by a cold and rainy winter and a hot summer.

Table 1 : Heating and cooling degree days for Medea (1995-2004).

\begin{tabular}{lrrr}
\hline HDD $15^{\circ}$ & 996.9 & CDD $26^{\circ}$ & 285.7 \\
\hline
\end{tabular}

HDD 15 is heating Degree days with a base temperature of $15^{\circ} \mathrm{C}$, and CDD21 is the Cooling Degree Days with a base temperature of $26^{\circ} \mathrm{C}$. It is clear that the main orientation for reducing energy demand is to improve the insulation of the apartment and to maximize the solar gains assured by a good orientation and windows more efficient.

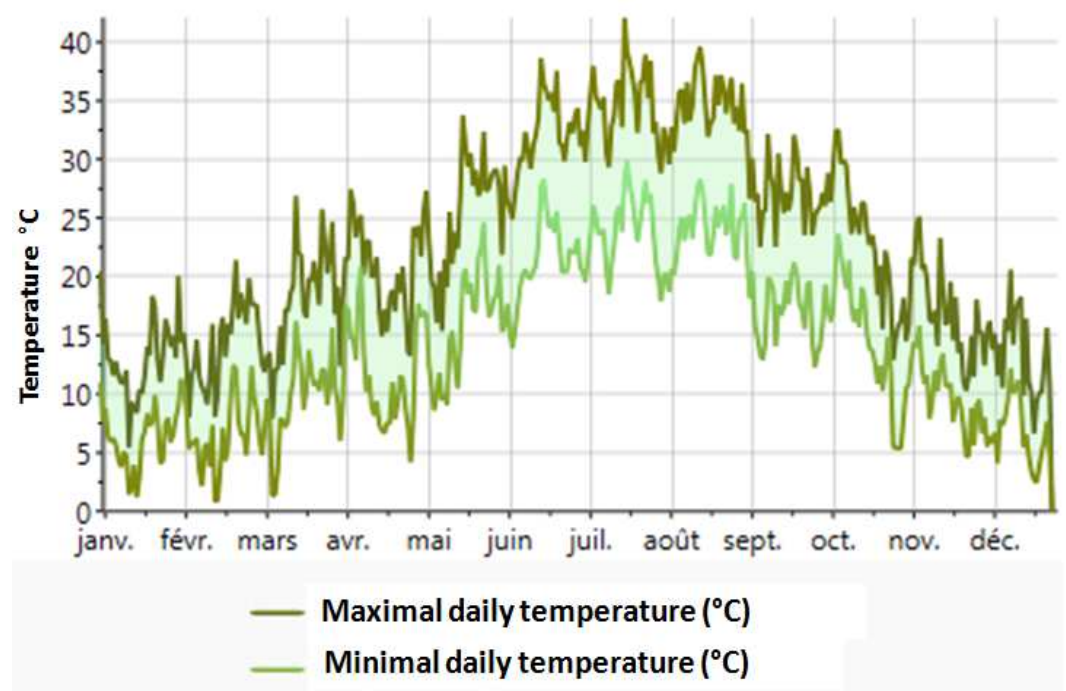

Figure 2 : Temperature of Médéa for the period of (2000-2009) using Meteonorm. 


\section{Results and discussion}

\subsection{Case study}

In this paper we have considered three cases. The first two apartments were constructed in 1972 where the insulation legislation did not exist yet, whereas the third one erected in 2006 after the insulation lawmaking was adopted. The apartment's floorplan and spaces are presented in the table 2 below:
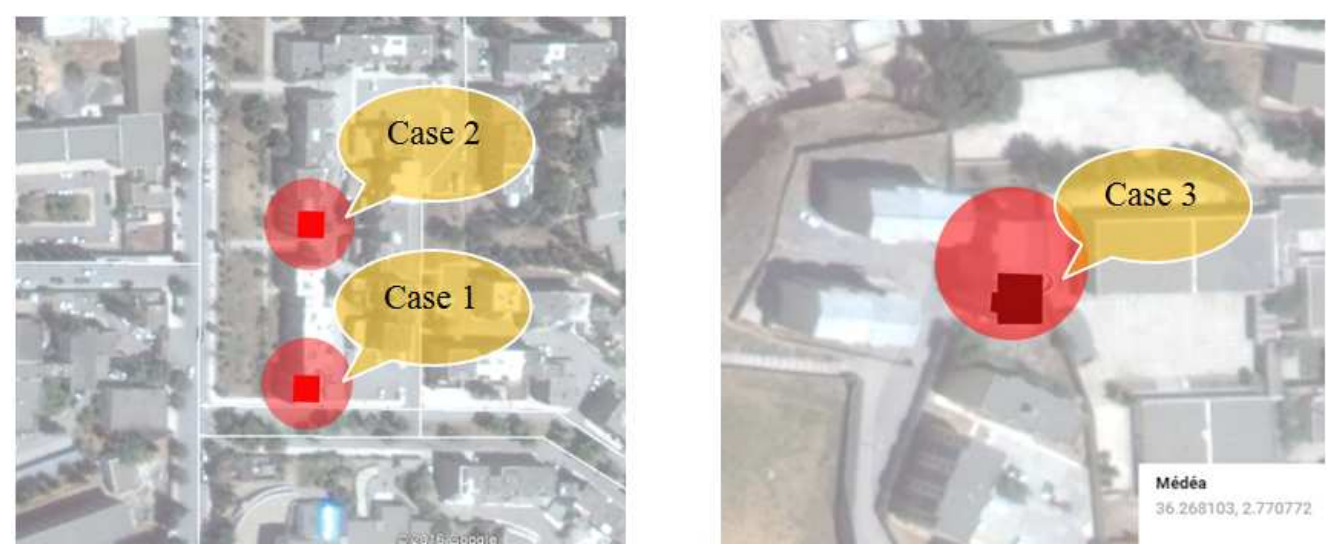

Figure 3 : The surrounding areas of building.

Table 2: Apartment modifications and energy load for the cases of the study.

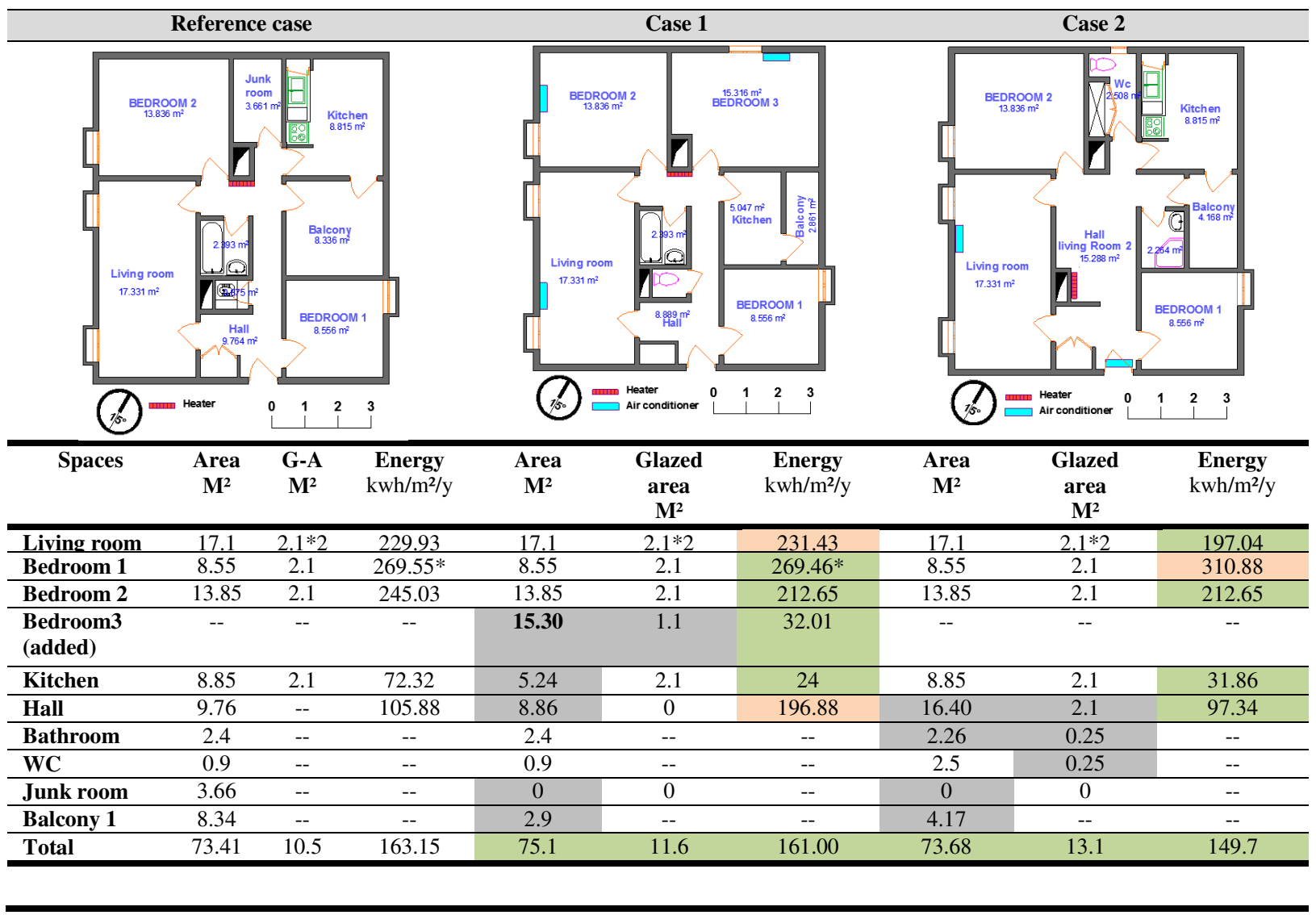




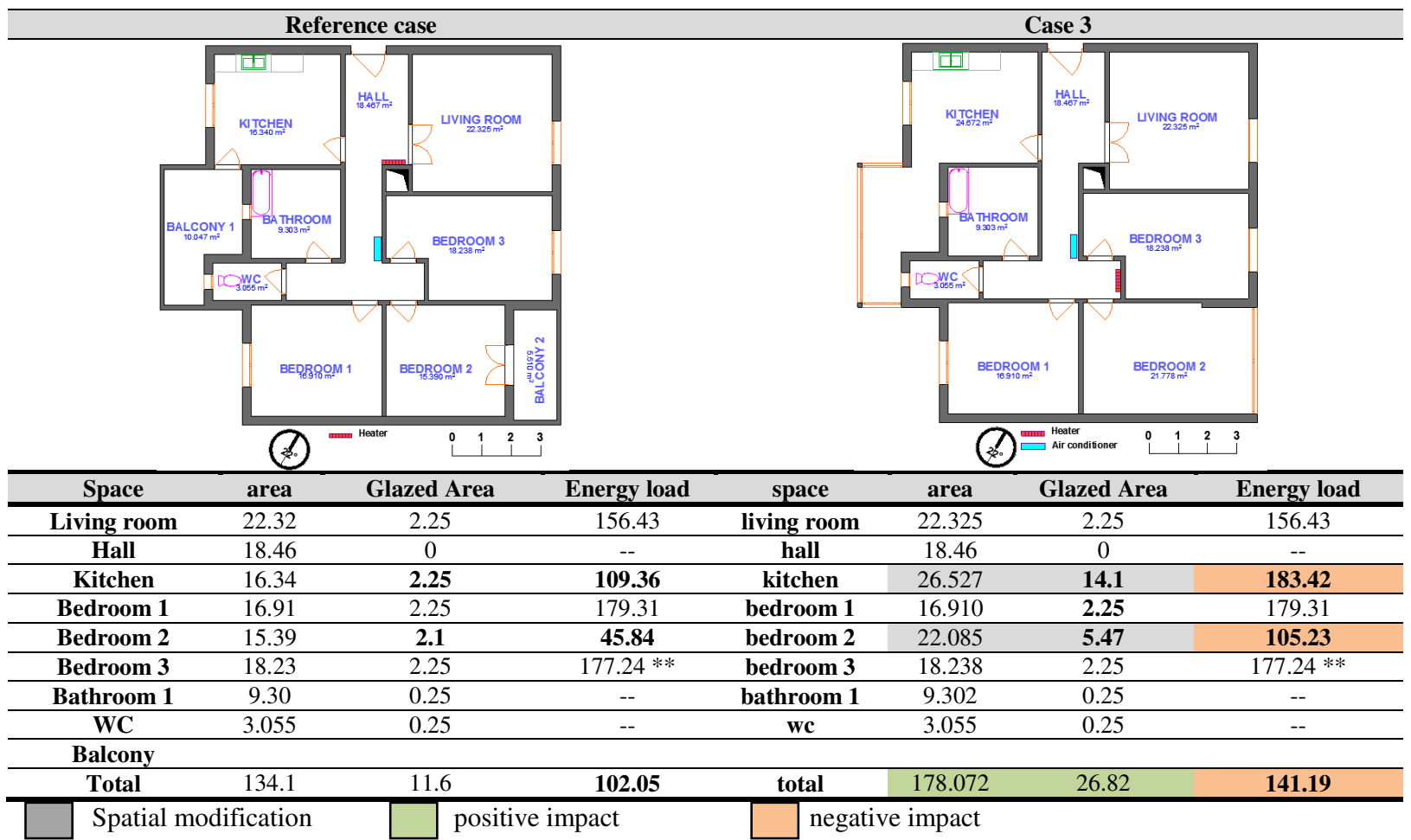

* The yearly energy load of the bedroom 1 is almost the same but the heating energy demand decreases for the case one from 175.45 to $166.34 \mathrm{kwh} / \mathrm{m}^{2}$ because the loss area is reduced for the case 1 in comparison to the reference case. And the cooling energy demand increases for the case 1 in comparison to the reference case from 94.10 to $103.12 \mathrm{kwh} / \mathrm{m}^{2}$.y because the walls are not insulated neither for the bathroom and nor for the bedroom 1 (see the fig. 3 below).

** the bedroom 3 in the case 3 and its reference has the same energy demand even if the bedroom 3 is in contact with the balcony 1 area for the reference case. The explanation is reported to the insulation level which is mandatory for the buildings erected after 1997.

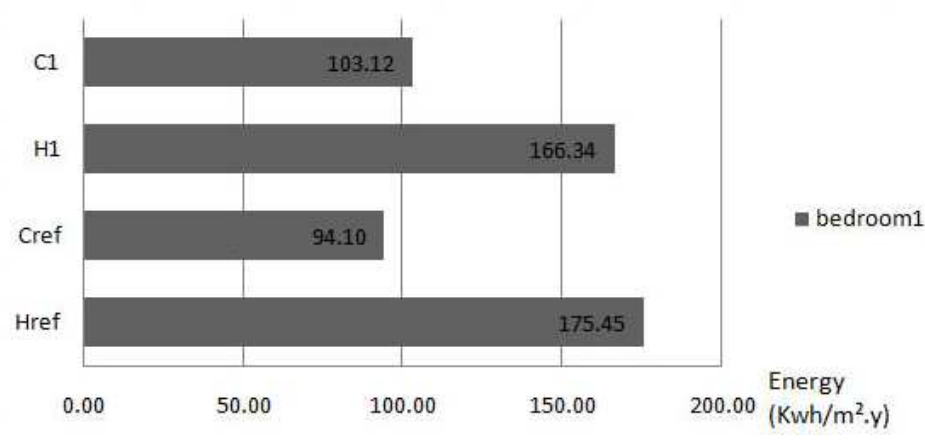

Figure 4 : The energy requirement of the bedroom for the case 1 and reference case. $\mathrm{C}$ : Cooling, H: Heating.

\subsection{Spatial adjustments made by occupants}

In our case, Adjustments are presented in the table 2 detecting those made and whether it has a negative or positive impact on energy load of dwellings. In the three cases, the balcony area presents the main modification possibilities for the three cases. The glazing area has been also 
increased. Mainly, case one and two have a positive impact, while the third one has a negative impact on energy demand.

\subsection{Materials characteristics used for simulation:}

We considered the same material characteristics used in the construction system of the three apartments as presented on the table below. Considering the lack of insulation due to legislative deficiency in 1970s, the two primary cases are not insulated whereas in the third, using a double brick cavity render according to the technical-regulatory document [9] which recommends this kind of insulation for the external walls.

Table 3: Material characteristics used for simulation

\begin{tabular}{|c|c|c|c|c|}
\hline Building element & Materials (case 1-2) & $\begin{array}{c}\mathbf{U} \\
\mathbf{w} / \mathbf{m}^{2} . \mathbf{k}\end{array}$ & $\begin{array}{c}\text { Materials } \\
\text { (case 3) }\end{array}$ & $\begin{array}{c}\mathbf{U} \\
\mathbf{w} / \mathbf{m}^{2} \cdot k\end{array}$ \\
\hline External Walls & Bricks (simple) & 3.01 & Double brick cavity render & 1.34 \\
\hline Internal walls & Bricks simple & 3.01 & Brick plaster & 2.3 \\
\hline Window & Single glazed timber frame & 5.35 & Single glazed timber frame & 5.4 \\
\hline Door & Solid core & 2.3 & Solid core pine timber & 2.3 \\
\hline Ceiling & Composite ceiling & 0.2 & concrete & 1.95 \\
\hline Floor & Composite floor & 1.51 & Concrete on ground & 0.48 \\
\hline
\end{tabular}

\subsection{Simulation energy load, a physical approach}

The energy load of the first two cases has a positive impact on the energy load based on simulations' data with $-1.34 \%$ and $-8.99 \%$ for case one and two respectively. The third case increases the energy load of the apartment by $27.72 \%$.

Case one and two have reduced the loss area by using half of the balcony area as an interior space. In the first case, the occupant transformed a half balcony area to a kitchen, and in the second case to a bathroom. In the two cases the apartments were more compact than before modifications. By adopting this modification, the loss area was reduced to half as presented in Fig. 5.

In the first case the energy load of bedroom 2, bedroom 1 and the kitchen was improved, while the energy load of the lobby increased. For the second case, the energy load of bedroom 1 , kitchen and the lobby was reduced while it increased for the bedroom 1 .

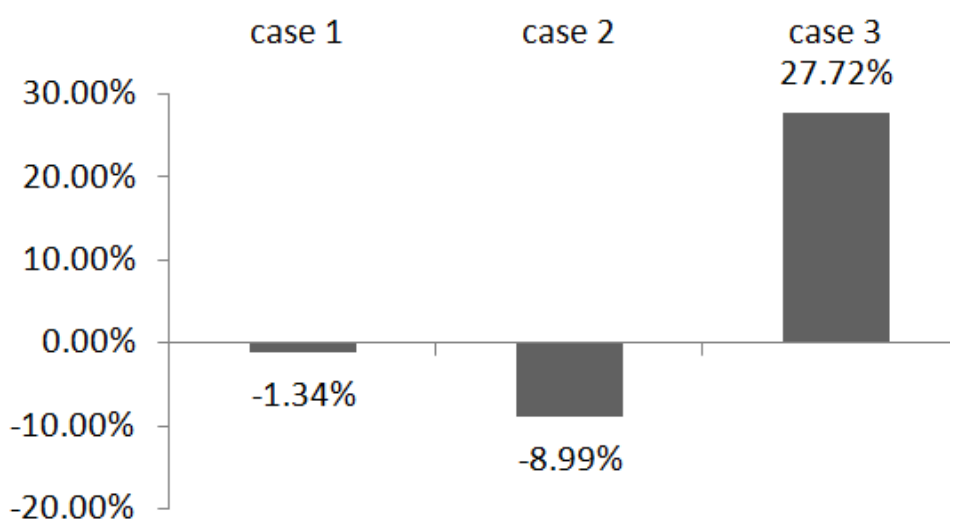

Figure 5 : Difference between the three modified cases and their reference cases. 


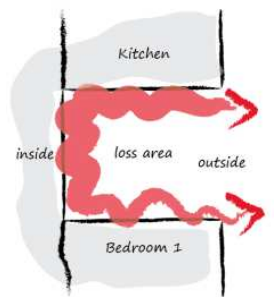

Before

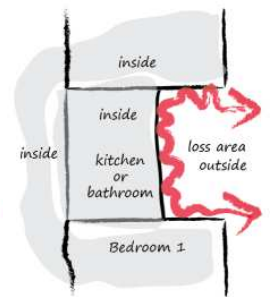

after

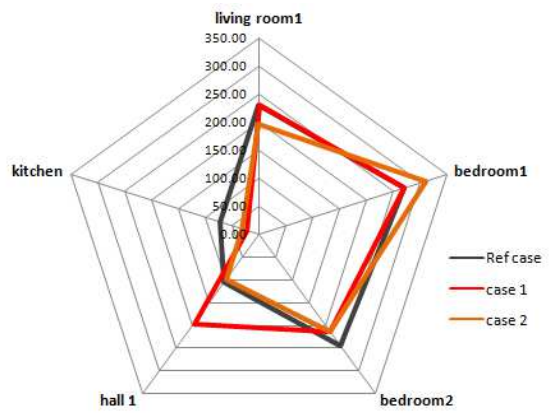

Figure 6 : The loss area before and after modification.

Figure 7 : Comparison between the case 1, 2 and the reference per space.

In the third case, an increasing of the energy load for all the apartments is observed. Mainly, the occupant made three adjustments. (i) Removing two balconies that had a solar protective role. (ii) Gaining more functional areas, case of the bedroom 2 used as a living room going from $15.4 \mathrm{~m}^{2}$ to $22 \mathrm{~m}^{2}$ meanwhile the principal living room is used to receive the guests mainly. Likewise, the kitchen became more spacious, by getting the entire balcony 1 area $\left(10 \mathrm{~m}^{2}\right)$. (iii) Increasing the glazed area for bedroom $2\left(2.1 \mathrm{~m}^{2}\right.$ to $\left.5.47 \mathrm{~m}^{2}\right)$ also for the kitchen going from $2.25 \mathrm{~m}^{2}$ to $14.1 \mathrm{~m}^{2}$. The windows are all made from single glazed and timber frame. the results showed that the energy demand of the architect design is $102 \mathrm{kwh} / \mathrm{m}^{2} / \mathrm{y}$, while the modified design increased the energy demand up to $141 \mathrm{kwh} / \mathrm{m}^{2} / \mathrm{y}$.

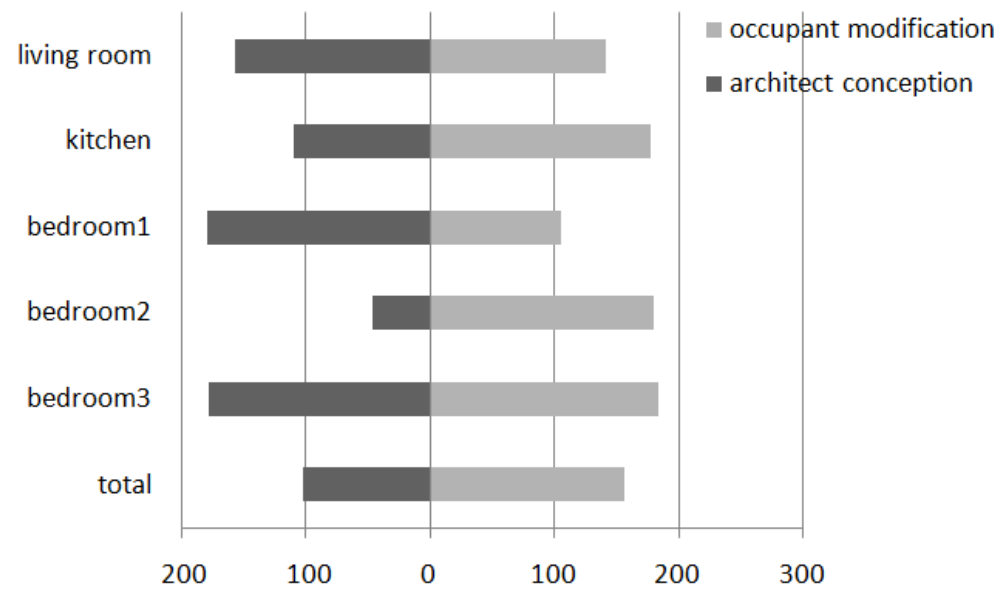

Figure 8 : Initial and modified apartment, case 3.

These results indicate that the occupant transformations increased the energy load of the dwelling by $38 \%$ with a ratio of $34 \%$ and $41 \%$ for heating and cooling respectively. The raise of the heating energy load can be explained by the increased glazed area which aggravates the thermal losses. Also, the cooling energy load increases also due to the importance of the glazed area, the insulation level and the removal of balconies which played a solar protection role by assuring shaded areas.

Through a careful examination, the energy load of the kitchen and the bedroom 2, we find respectively, a raise of the energy load by $67 \%$ and $133 \%$. However, if we just change the level of insulation by changing the single glazed window to double glazed and timber frame window (u-value $2.9 \mathrm{w} / \mathrm{m}^{2} . \mathrm{k}$ ), we obtain $110 \mathrm{kwh} / \mathrm{m}^{2} / \mathrm{y}$ which means an increasing of $9 \%$ 
instead of $38 \%$. Our results concord with [3] which states that the energy saving could increase from 33 up to $60 \%$ due to the insulation improvement and [14] estimated that the building stock lacking in insulation would save until $49 \%$ of the initial energy consumption for heating.

\subsection{Energy load using end-use approach}

By using the energy demand based on the energy end-use, the differences are important between the three apartments. Energy load was reduced for all cases except for case one and three where we recognize a major difference.

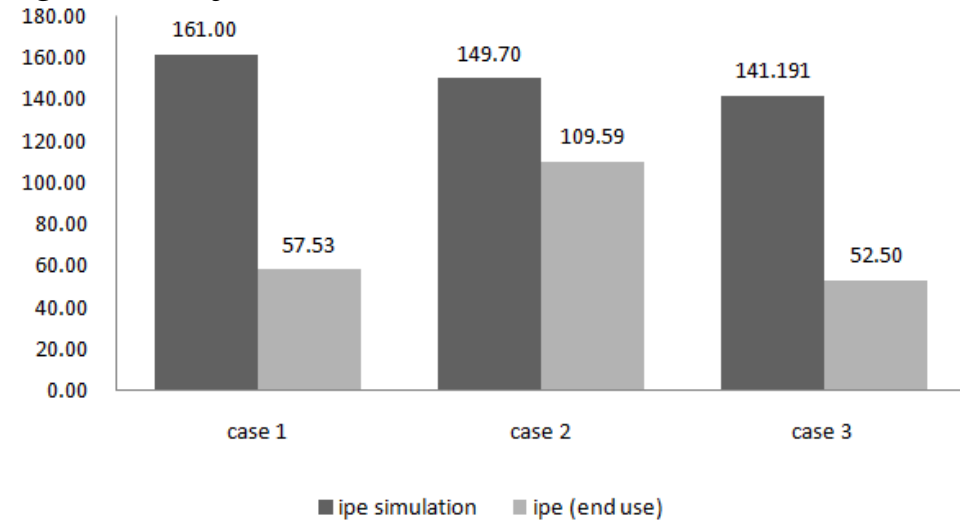

Figure 9 : Difference between EPIs (Energy Performance Index simulated vs end use)

Using summer and winter's energy consumption bills, we have got the mean energy end use for the year. As for case 1 has $57.53 \mathrm{kwh} / \mathrm{m}^{2} / \mathrm{y}$ and $52.50 \mathrm{kwh} / \mathrm{m}^{2} / \mathrm{y}$ for case 3 . It means that the two cases have an austerity lifestyle [7]. But when we identified the occupancy schedule of the occupant for the two apartments we discovered that case one is full-time occupied, while case three is occupied from 16h to 7:30 every working day except the weekends where the dwelling is full time occupied. Here is to say that even if case 3 presents the lowest energy load but its consumption intensity at home is more important than case 1 . Case 2 remains close to the simulated energy load with $109.59 \mathrm{kwh} / \mathrm{m}^{2} / \mathrm{y}$. The occupancy schedule of the case 2 is also full time.

\subsection{The difference with the national mean of energy load:}

The mean national energy consumption for Algeria is estimated at $151 \mathrm{kwh} / \mathrm{m}^{2} / \mathrm{y}$ including all housing typologies [8]. For the case of Algiers and for a dwelling of $66 \mathrm{~m}^{2}$ and occupied by 4 persons, the annual energy load of electricity is estimated to $2200 \mathrm{kwh}$ per year and $15.2 \mathrm{~m}^{3}$ for gas $/ \mathrm{m}^{2} / \mathrm{y}$ [2] which gives an energy performance index (EPI) of $191.41 \mathrm{kwh} / \mathrm{m}^{2} . \mathrm{y}$. 


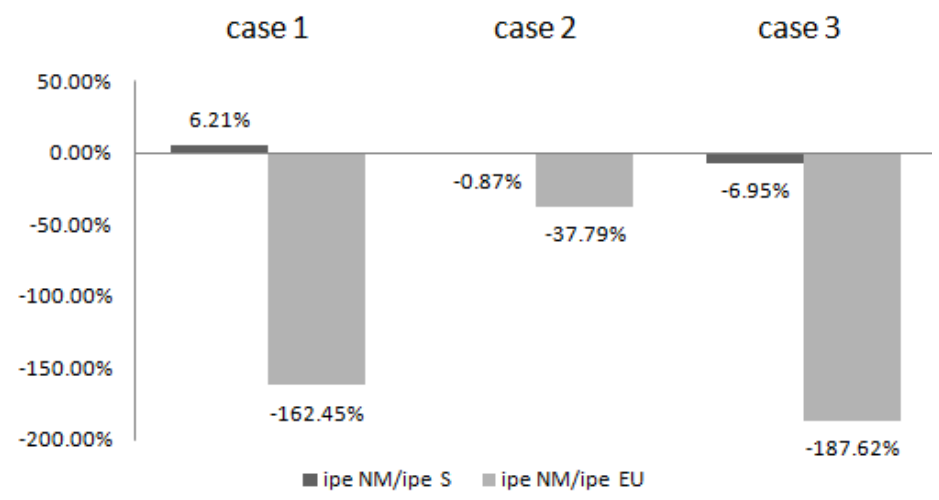

Figure 10 : Percentage difference between EPIs and national mean. With $\mathrm{S}$ is energy demand obtained using simulations and EU is the measured energy end-use.

In our case located in Medea city, we have used the national mean of energy and as we can see in Fig. 9, the simulated estimation is not far from the national mean with 6.21, - 0.87 and $6.95 \%$ respectively for case 1,2 and 3 . However, the difference is more important using the energy end-use where a reduction of $-162.45 \%,-37.79$ and $-187.62 \%$ for case 1,2 and 3 respectively. If we take national means as standard lifestyle, we can estimate that the three cases have an austerity lifestyle and they aim to save energy.

\subsection{A socio-economic explanation:}

This section provides a socio-economic explanation to the energy load estimated either by simulation or by end use. The analysis is made on a comparative way based on the: (i) Energy Performance Index (EPI), (ii) Rate of Occupant per Housing (ROH), (iii) the income per housing and per person (vi) the number of dwellers per housing. The results are shown on the figure below.

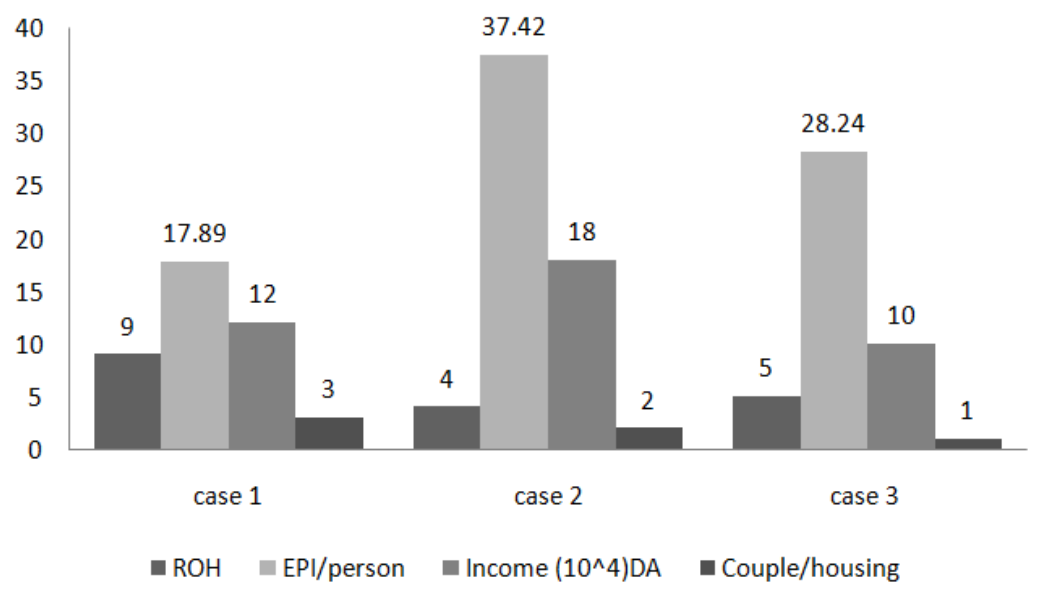

Figure 11 : Socio-economic comparison.

Fig. 10 shows three profiles: The rate of occupant by housing is 9,4 and 5 for the case 1,2 and 3 respectively. It seems like when the occupancy rate increases the EPI per person decreases. We have performed a scatter plot diagram, Fig. 11 and 12, to verify this assumption and it appears that the determination coefficient $\mathrm{R}^{2}$ is $91.3 \%$ for the simulation approach and $35 \%$ for the end-use energy which both are important values. Hypothesis on people density are 
verified on urban scale $[12,15]$, meanwhile a negative correlation tends to submit reduction on housing scale. Even if it is true we cannot imagine this conclusion as a spreading solution because a density of 9 persons per housing in $73 \mathrm{~m}^{2}$ is not pleasant to be considered as a practical solution.

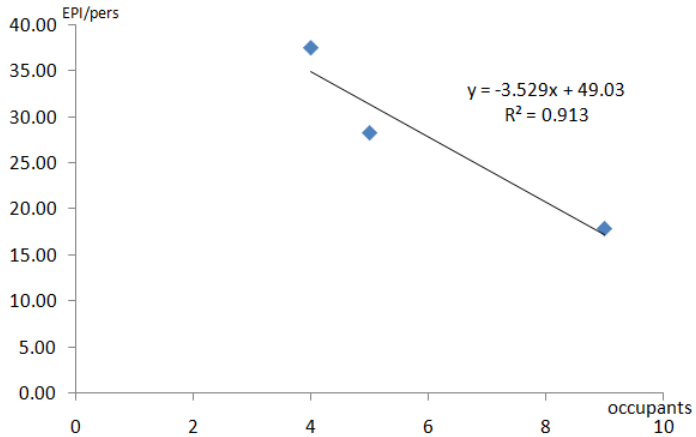

Figure 12 : Correlation between EPI (simulation) and $\mathrm{ROH}$.

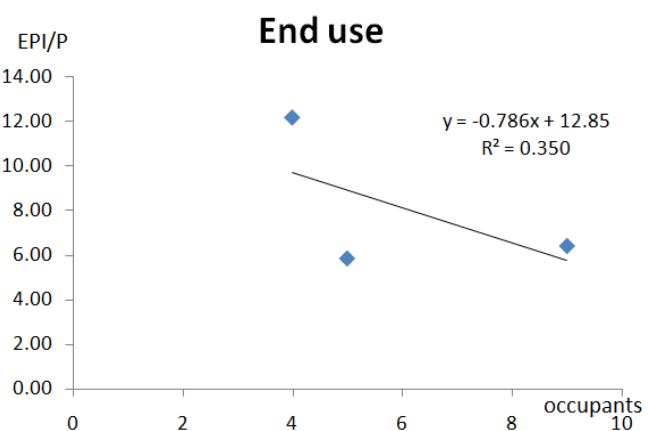

Figure 13 : Correlation between EPI (end use) and $\mathrm{ROH}$ (rate of occupancy)

The income also plays an important role in the consumption phenomenon, but here in our paper we note that the determination coefficient is positive with the income which means that when the income increases the energy consumption increases as well. This claim is verified for the simulated approach with an $\mathrm{R}^{2}$ of about $87.7 \%$. Also, when we correlate the EPI/person with the income/person using the energy end use instead of the simulated one, the result shows a remarkable increase of the $\mathrm{R}^{2}$ reaching $99.9 \%$, indicating that the income is the most important factor explaining the energy end-use in our cases of study.

These conclusions concords with Singh [13] founding that socio-economic characteristics and behaviour could explain $28.8 \%$ variation in heating/cooling energy consumption. Three cases are not sufficient to precise with more accuracy the impact of the income on the energy load of flat but the tendency is however confirmed.

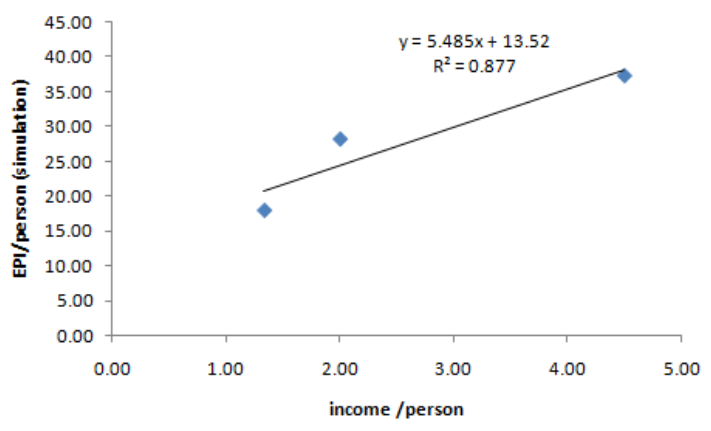

Figure 12 : Correlation between EPI (simulation) and income.

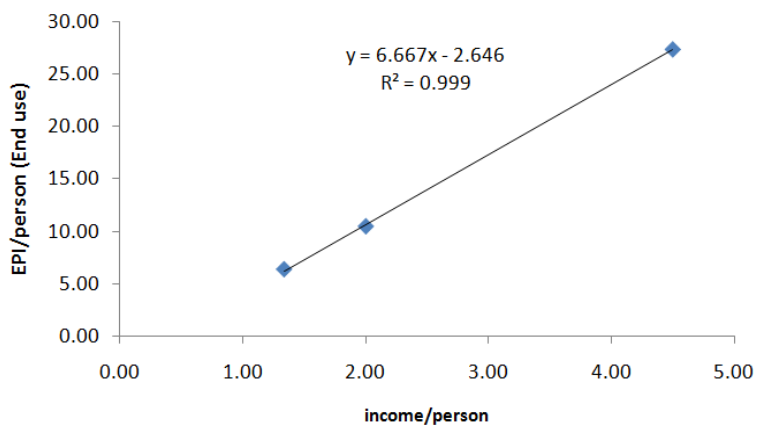

Figure 13 : Correlation between EPI (End use) and income.

The number of households per housing also seems to affect the energy use. In our cases, we have three, two and one family for case one, two and three respectively and it seems that the energy load is negatively correlated with the number of family members or couple per housing. During last period, the Algerian government is projecting to get an occupancy rate of 
five persons per housing. The national mean of occupancy rate per housing is still above this goal and we will continue to see these cases until the achieving of the program of three million housing.

\subsection{Greenhouse Gas Emission:}

In this section we have also singled out the Greenhouse Gas emission for the simulated, measured and the national mean. We have acquired the emission factors of Gas and Electricity from the international energy agency (2008) which reported the international emission factors of greenhouse gas [1]. The emission factor of Electricity is 188 g equivalent Carbon per $1 \mathrm{kwh}$, and $206 \mathrm{~g}$ by $1 \mathrm{kwh}$ of Gas.

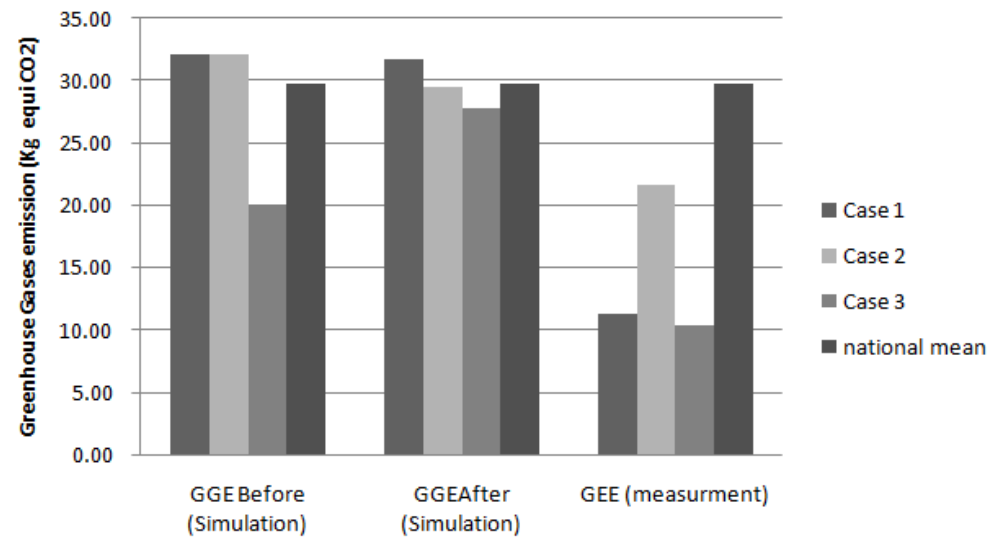

Figure 1 : Greenhouse Gases emissions ( $\mathrm{kg} \mathrm{CO} 2$ equivalent $\left./ \mathrm{m}^{2} . \mathrm{y}\right)$

The greenhouse gas emissions for the national mean seem to be the most important between the three cases of our study. Within the simulation approach and before modifications, the Greenhouse Gases emissions (GHG) for the case 1 and 2 are superior than the national mean, while the third case is inferior with $20 \mathrm{~kg}\left(\mathrm{CO} 2 / \mathrm{m}^{2} / \mathrm{y}\right)$. With the modifications made by occupant, the GHG's case one still remains more important comparing to the national mean. Meanwhile, the case 2 emits less GHG than before modification. The GHG's case 3 increases because of the occupant modifications. On the other hand, and for the measurement approach, the three cases seem to have a GHG inferior to the national mean. However, the case 2 presents the most important GHG with $21.59 \mathrm{~kg}\left(\mathrm{CO} 2 / \mathrm{m}^{2} / \mathrm{y}\right)$ and a difference with the case 1 and 3 more than $10 \mathrm{Kg}\left(\mathrm{CO} 2 / \mathrm{m}^{2} / \mathrm{y}\right)$.

\section{Conclusion}

In this paper, we firstly highlighted the phenomenon of non-controlled housing spatial modification which is widespread in Algeria. Secondly, we singled out the energy load of the occupant spatial modification via a comparison between the architect design and the modified one in two ways, (i) energy acquired from simulations using Ecotect software and (ii) The energy load using the end-use. Basically, adjustments can either increase or decrease the energy demand of the dwellings.

The cases studied have two positive and one negative impacts. Adopting modification for more functional reasons. (a) The physical argue for the three cases seems to be the quality of 
the envelope insulation that the occupant does not have the necessary skills to improve. Unwittingly, for the case one and two, the reduced thermal losses are due to the decreased area gained after occupant modification. Whereas, for the third case, glazing was increased without any solar protection. (b) The socio-economic explanation shows more understanding reasons. The density of households per housing plays a major role in energy load but the most relevant factor is the income which explains within the two approaches more than $87 \%$ of the energy consumption. Obviously, modifications made by occupants in their housings have a considerable impact on the energy demand.

Referring to the cases studied proficient need to be notified in order to establish mediations that conform occupant expectations. Via this paper three cases were presented aiming to enlarge the cases number by introducing new occupant's comfort strategies. Finally, it's very important not only to set mechanisms that motivate the occupant to alter their modification style far from extemporizing, but to involve experts' consultations as well by implementing a clear legislative to frame this kind of occupant behavior.

\section{Acknowledgements}

We would like to thank the three families for the help and the assistance they provided to us to be able to do this research.

\section{References}

[1] ADEME, (2010). Bilan Carbone ${ }^{\circledR}$, Entreprise et collectivités, Guide des facteurs d'émission, $V$ 6.1, Chapter 2, France.

[2] Bouamama Wahiba, (2013). Au Sujet De La Politique D'efficacité Energétique En Algérie : Approche Systémique Pour Un Développement Durable.Cas De : Programme Eco-Bat Cnerib. Magister thesis, University of Tlemcen, Algeria.

[3] Chen S Yoshino H Levine M D Li Z, . Contrastive analyses on annual energy consumption characteristics and the influence mechanism between new and old residential buildings in Shanghai, China, by the statistical methods. Energy and Buildings, 41(12), 1347-1359.

[4] Christensen J H H ewitson B Busuioc A Chen A Gao X Held R Magaña Rueda V, (2007). Regional climate projections. In Climate Change, 2007: The Physical Science Basis. Contribution of Working group I to the Fourth Assessment Report of the Intergovernmental Panel on Climate Change. U . (str. 847-940). University Press, Cambridge, Chapter 11.

[5] Emery.A Kippenhan C., (2006). A long-term study of residential home heating consumption and the effect of occupant behavior on homes in the Pacific Northwest constructed according to improved thermal standards. Energy, 31(5), 677-693.

[6] Hassanabadi M S Banihashemi S \& Javaheri A R. Analysis and comparison of impacts of design optimization approaches with occupant behavior on energy consumption reduction in residential buildings. International. Journal of Engineering and Technology, 4(6),

[7] Hong, T, (2013), Occupant behavior: impact on energy use of private offices-1st Asia conference of International Building Performance Simulation Association, Shanghai, China.

[8] KHARCHI Razika, (2013). L'efficacité énergétique dans le bâtiment. Recherche et Développement, CDER, 28.

[9] Ministery of habitat, (1997). Document technique réglementaire (DTR C3-2). Algeria. 
[10] National agency for the promotion and energy use rationalization (APRUE), (2012). Consommation énergétique finale de l'Algérie. retrieved from http://www.Aprue.org.dz/

[11] Ouyang J \& Hokao K, (2009). Energy-saving potential by improving occupants' behavior in urban residential sector in Hangzhou City, China. Energy and Buildings, 41(7), 711-720.

[12] Serge Salat, (2011). Les villes et les formes urbaines : Sur l'urbanisme durable, Hermann. France.

[13] Singh M K Mahapatra S Teller J, (2013). An analysis on energy efficiency initiatives in the building stock of Liege, Belgium. Energy policy, 62, 729-741.

[14] Swan L G Ugursal V I, (2009). Modeling of end-use energy consumption in the residential sector: A review of modeling techniques. Renewable and sustainable energy reviews, 13(8), 1819-1835.

[15] Steemers, K. (2003). Energy and the city: density, buildings and transport. Energy and buildings, 35(1), 3-14.

[16] Yu Z Fung., B Haghighat., F Yoshino H Morofsky E, (2011). A systematic procedure to study the influence of occupant behavior on building energy consumption. Energy and Buildings, 43(6), 1409-1417.

[17] Boukarta, S., \& Berezowska, E. (2017). Exploring the Energy Implication of Urban Density in Residential Buildings. Journal of Applied Engineering Sciences, 7(1), 7-14. 